\title{
Hereditary amyloidosis with primary renal involvement
}

INSERM

\section{Source}

INSERM. (1999). Orphanet: an online rare disease and orphan drug data base. Hereditary amyloidosis with primary renal involvement. ORPHA:85450

A group of rare renal diseases, characterized by amyloid fibril deposition of apolipoprotein A-I or A-II (AApoAI or AApoAll amyloidosis), lysozyme (ALys amyloidosis) or fibrinog en A-alpha chain (AFib amyloidosis) in one or several organs. Renal involvement leading to chronic renal disease and renal failure is a common sign. Additional manifestations depend on the organ involved and the type of amyloid fibrils deposited. 